\title{
Aportes de Richard Rorty para la organización de una biblioteca pública
}

\section{Richard Rorty's contributions to the organization of a public library}

Juan José Ramírez ${ }^{1}$

\begin{abstract}
No hay universo en el sentido orgánico, unificador, que tiene esa ambiciosa palabra. Si lo hay, falta conjeturar su propósito; falta conjeturar las palabras, las definiciones, las etimologías, las sinonimias, del secreto diccionario de Dios.
\end{abstract}

(J. L. Borges, Otras inquisiciones, 1952)

\section{Resumen}

En el contexto del neopragmatismo de Richard Rorty, se analiza una propuesta alternativa a los criterios habituales para la organización de una biblioteca. Se pretende mostrar cómo, en el marco de esa proposición, pueden catalogarse textos en función de sus usos y cómo las denominadas obras de ficción pueden constituirse en un aporte útil para una educación democrática.

En la historia de la cultura, existen textos con propósitos muy diferentes. Encontramos escritos cuya intención apunta a promover un determinado tipo de conducta para la vida pública y textos que buscan satisfacer el deseo de la autonomía privada de los individuos. Entre los primeros, están, entre otros, los tratados filosóficos, los manuales de conducta moral y el tipo de escritos que prescriben conductas deseables para

\footnotetext{
${ }^{1}$ Doctor en Ciencia Política. Licenciado en Filosofía. Licenciado en Ciencias de la Educación. Docente de la Universidad Católica de Córdoba. Córdoba, Argentina. Correo electrónico: jjrcba@hotmail.com
}

Diälogas Pedagógicas - ISSN en línea: 2524-9274.

Año XIX, No 37, abril-septiembre 2021. Pág. 27-39. DOI: http://dx.doi.org/10.22529/dp.2021.19(37)03 Recibido: 21-06-2020 / Aprobado: 07-04-2021. 
la vida pública; entre los segundos, podemos encontrar las denominadas obras de ficción y ensayos cuya intención es mostrar, con minuciosidad, cómo se desenvuelven algunas formas de vida en la búsqueda de la perfección privada El presente trabajo sugiere la posibilidad de que los tratados filosóficos y las grandes obras teológicas, lo mismo que los manuales de moral o los escritos científicos, pueden ser considerados como contribuciones para nuestras fantasías privadas; mientras que géneros como la novela, el cuento o los ensayos periodísticos pueden resultar particularmente provechosos para estimular conductas sociales.

Palabras clave: biblioteca, liberalismo, democracia, novela.

\begin{abstract}
In the context of Richard Rorty's neopragmatism, an alternative to the usual criteria for organizing a library is offered. It is intended to show how texts can be cataloged according to their uses, and how the so-called works of fiction can become a useful contribution to a democratic education.

In the history of culture, there are texts with very different purposes. We find writings whose intention is to promote a certain type of conduct for public life, and texts that seek to satisfy the desire for the private autonomy of individuals. Among the former, there are, among others, the philosophical treatises, the manuals of moral conduct, and the type of writings that prescribe desirable conducts for public life. Among the latter, we can find the so-called works of fiction and essays whose intention is to show, in detail, how some forms of life unfold in the search for private perfection. This work suggests the possibility that philosophical treatises and great theological works, as well as moral manuals or scientific writings, can be considered as contributions to our private fantasies; while genres such as novels, short stories, or journalistic essays can be particularly helpful in stimulating social behaviors.
\end{abstract}

Keywords: library, liberalism, democracy, novel.

\title{
Introducción
}

El presente trabajo se organiza en cuatro partes. En la primera parte y a partir de un texto autobiográfico de Richard Rorty, se ofrecen argumentos para sostener la conveniencia de la distinción entre el ámbito público y el privado. En un segundo apartado, se describe la figura rortyana del ironista liberal. A partir de esta figura, se insinúa la idea de que, en una cultura ironista y liberal, los textos pueden ser catalogados no según criterios enciclopédicos con disposiciones metafísicas, sino según el uso que se les pudiera dar. En un tercer momento, se pretende ofrecer un criterio para la organización de textos congruente con los rasgos de una cultura ironista liberal. En la cuarta y última parte, se sugiere la consideración de los denominados textos de ficción como obras que pueden resultar de utilidad no para proyectos privados, sino para fines públicos. 


\section{Un proyecto imposible: Trotsky y las orquídeas o la síntesis de lo público y lo privado}

En un trabajo autobiográfico de 1992, Trotsky and the Wild Orchids², Richard Rorty aclara las razones de su perspectiva respecto de la relación entre filosofía y política. Rorty dice haber sido educado en una familia comprometida activamente con valores políticos que promovían un sentido de la justicia social emparentado con el pensamiento trotskista o, al menos, socialista de la época. La importancia que tuvo para él la sensibilidad social se pone de relieve en sus propias palabras: "A los doce años yo ya sabía que el sentido de la vida era luchar contra la injusticia social" (Rorty, 1998, p. 31). Independientemente de su compromiso público con determinados valores sociales, el joven Rorty tenía -también- intereses privados que, según él mismo relata, se dirigían a las orquídeas silvestres que crecían en las montañas del noroeste de Nueva Jersey.

Una de las primeras tareas intelectuales del joven Rorty consistió en el intento de conciliar, o al menos relacionar de un modo no reprochable, su compromiso social con sus intereses privados. En este sentido, "tenía un proyecto en mente: reconciliar a Trotsky y las orquídeas." (Rorty, 1998, p. 31). Para llevar a cabo aquel proyecto, debió rebelarse contra el pragmatismo en el que había sido educado por sus padres. Rorty consideraba, en su juventud, que aquellas ideas no eran capaces de ofrecer un fundamento absoluto e irrefutable para sus opciones sociales. Abandonando el pragmatismo por su incapacidad para argumentar de un modo convincente sobre sus intereses políticos, el norteamericano se lanza a buscar las bases absolutas que le permitiesen explicar sus preferencias políticas.

En aquella búsqueda, el joven Rorty advierte tempranamente que esos absolutos filosóficos y morales eran, al igual que sus orquídeas silvestres, difíciles de encontrar y se topa con la dificultad de justificar de modo no circular los temas de debate. Lo que ocurre es que advierte que cada uno de los intelectuales en los que buscaba herramientas para concretar su proyecto de reconciliar sus preferencias políticas con sus intereses privados "podía retrotraer sus puntos de vista a primeros principios que resultaban incompatibles con los primeros principios de sus oponentes y que ninguno de ellos lograba llegar nunca a ese lugar fabuloso más allá de las hipótesis" (Rorty, 1998 , p. 35).

Advertido de la imposibilidad de argumentar de modo no circular a favor de sus preferencias morales y políticas, Rorty decide que la prueba de una verdad no se halla tanto en la deducción lógica de principios incuestionables como en la coherencia de la propuesta. Puede decirse que es entonces cuando abandona las inferencias lógicas del método propio de los metafísicos (Rorty, 1991, p. 96). El abandono de la búsqueda de primeros principios evidentes y absolutos para concretizar su proyecto no fue suficiente para abandonar el proyecto en sí, pero sí para abandonar lo que Rorty considera el pensamiento de los absolutos asociado a la filosofía platónica.

En el descubrimiento de la Fenomenología del espíritu (Hegel, 1807), Rorty encuentra la posibilidad de rencauzar su proyecto filosófico de una manera menos pre-

\footnotetext{
2 Rorty, Richard. Trotsky and the Wild Orchids en Common Knowledge, Vol 1, No 3 invierno pp. 140-153. 1992. La versión en español que se utiliza aquí corresponde a Rorty, Richard. Trotsky y las orquídeas silvestres en Pragmatismo y política. Traducción al español de Rafael del Águila. Paidós, Barcelona 1998.
} 
tenciosa. Con el hallazgo de Hegel, el plan de armonizar lo público con lo privado abandona su matriz metafísica para adoptar un giro historicista (Rorty, 1991, p. 15). El objetivo sigue siendo el mismo: reconciliar los intereses privados con la vida pública, solo que ahora ya no perseguiría la búsqueda de principios evidentes y absolutos, sino que se contentaría con encontrar en la filosofía de su tiempo las razones para hacer del mundo un lugar mejor. Sin embargo, al poco tiempo, se descubre retornando a aqueIlas ideas en las que había sido formado por sus padres y contra las que se había revelado tempranamente, esto es, al pragmatismo de John Dewey. Este retorno coincide con el encuentro de Derrida y el hallazgo de importantes semejanzas entre Dewey, Derrida, Heidegger y Wittgenstein en la crítica a la filosofía platónico-cartesiana. La reconciliación con el pensamiento de Dewey lleva a Rorty a la idea de que su proyecto filosófico de reconciliar los intereses privados con la vida pública no había fallado por errores de ejecución. No es que él no haya podido encontrar los argumentos filosóficos, la cuestión es que el proyecto en sí constituía una equivocación. En este sentido afirma: "Llegué a la convicción de que la idea misma de fundir realidad y justicia en una imagen única había sido un error" (Rorty, 1998, p. 38).

Según Rorty, en la historia de la cultura, existen obras con propósitos muy diferentes. Están los textos como los de Foucault y de Heidegger en los que predomina el deseo de autonomía privada y textos como los de Dewey y de Habermas cuya expectativa es la de promover el desarrollo de las instituciones democráticas. En el tipo de textos que escriben Heidegger o Foucault, lo decisivo es la pretensión de autonomía o de autenticidad como un rasgo distintivo de los intelectuales que desean ir más allá del límite que la educación y el entorno les han otorgado a sus creencias (Rorty, 2010, p. 165). En estos pensadores, la tendencia es considerar la socialización de los individuos en términos despectivos. Sin embargo, al mismo tiempo, hay otros pensadores como Dewey y Habermas que insisten en el deseo de una comunidad humana más justa y más libre. Estos pensadores pretenden vincular el producto de sus esfuerzos intelectuales con las formas de vida de la mayoría de las personas.

La propuesta rortyana ante la tensión entre lo público y lo privado es que "no intentemos elegir entre ellos, sino, más bien, darles la misma importancia y utilizarlos para diferentes propósitos" (Rorty, 1991, p. 16). Rorty considera que mientras algunos pensadores pueden resultar valiosos para ilustrar la autonomía del individuo que se crea y recrea a sí mismo, otros constituyen ejemplos valiosos del esfuerzo social por hacer que las instituciones y las prácticas públicas sean más justas y menos crueles. Para Rorty, no hay perspectiva filosófica que permita reunir -en una única concepciónlas respuestas a los interrogantes por la perfección privada con las propuestas para la creación de una sociedad más justa. Cualquier pretensión teórica de reunir en un único vocabulario propuestas públicas con recomendaciones privadas constituye un esfuerzo estéril. Para Rorty:

No hay forma de reunir a la creación de sí mismo con la justicia en el plano teórico. El léxico de la creación de sí mismo es necesariamente privado, no compartido, inadecuado para la argumentación. El léxico de la justicia es necesariamente público y compartido, un medio para el intercambio de argumentaciones. (Rorty, 1991, p. 16)

La renuncia a un discurso que pueda conciliar intereses privados y esperanzas sociales constituye, también, el abandono de la expectativa por realizar algún tipo de síntesis entre autores como Nietzsche y Heidegger con autores como Marx o Habermas. Esto se debe a que "la relación existente entre los autores que escriben acerca de 
la justicia y los que escriben acerca de la autonomía se asemeja a la relación existente entre dos tipos de instrumentos" (Rorty, 1991, p. 16). Se trata de instrumentos que responden a intereses diversos. El tipo de herramientas que construyen pensadores como Nietzsche, Heidegger o Foucault responde a propósitos muy diversos del instrumental construido por Marx, Dewey o Habermas. La primera secuencia de autores ejemplifica al tipo de pensadores que "nos hacen ver que las virtudes sociales no son las únicas virtudes (...) los del otro tipo nos advierten de las deficiencias de nuestras instituciones y prácticas [sociales]" (Rorty, 1991, p. 16).

\section{El ironista liberal}

La imposibilidad de sintetizar los intereses privados con las esperanzas públicas en un proyecto único redunda en el trazado de la figura que Rorty denomina el ironista liberal (Rorty, 1991, p. 139). Con el objeto de esclarecer esta figura, Rorty señala: "Empleo el término ironista para designar a esas personas que reconocen la contingencia de sus creencias y de sus deseos más fundamentales" (Rorty, 1991, p. 17). En lo que hace a la definición rortyana de liberal, el norteamericano sigue a Judith Shklar, para quien "los liberales son personas que piensan que los actos de crueldad son lo peor que se puede hacer" (Rorty, 1991, p. 17).

El ironista liberal es el tipo de persona que asume la imposibilidad de fundamentar sus propias esperanzas sociales de un modo no contingente, que tiene dudas radicales e insoslayables respecto del conjunto de palabras que emplea para justificar sus acciones, sus creencias y su modo de vida. Es aquel que no encuentra en su propio vocabulario algún argumento capaz de resolver o disolver las dudas sobre su propio léxico último, no concibe su propio vocabulario como más cercano a la realidad que otros vocabularios alternativos. Un ironista renuncia al intento de formular criterios para elegir entre léxicos últimos. Para él, "es posible hacer que cualquier cosa aparezca como buena o mala redescribiéndola" (Rorty, 1991, p. 92). El ironista es nominalista e historicista, descree de la posibilidad de encontrar criterios para elegir entre léxicos alternativos, asume su incapacidad para escapar del propio lenguaje y de la contingencia y de la historicidad de ese mismo lenguaje.

Para un ironista, que además es liberal, la vida de una sociedad liberal no se encuentra necesariamente emparentada con la racionalidad moderna y, en este sentido, cree posible seguir defendiendo las instituciones de una sociedad liberal aún después de haber abandonado el léxico de la Ilustración. Desde un punto de vista ironista, las libertades políticas que ofrece una sociedad liberal no requieren de fundamento racional. Para Rorty: "Desde nuestra perspectiva, lo único que importa para la política liberal es la convicción ampliamente compartida de que llamaremos verdadero o bueno a todo lo que resulte de la libre discusión" (Rorty, 1991, p. 102).

La expresión libre discusión hace referencia al tipo de debate que se desarrolla cuando las instituciones de una sociedad son libres y la comunicación social no tiene distorsiones. Se trata, simplemente, del tipo de discusión y comunicación que se logra cuando se dispone de instituciones políticas democráticas y de las condiciones que hacen posible que esas instituciones funcionen sin ningún tipo de limitación extrínseca. Para la cohesión de los miembros de una sociedad liberal, no se necesitan fundamentos metafísicos o epistemológicos, solo se requiere de herramientas que favorezcan la libre participación de esos ciudadanos en su entorno social: 
El aglutinante social que mantiene unida a la sociedad liberal ideal (...) consiste en poco más que el consenso en cuanto que a lo esencial de la organización social estriba en dar a todos la posibilidad de crearse a sí mismos según sus capacidades, y que esa meta requiere, aparte de paz y prosperidad, las libertades burguesas clásicas. Esa convicción no se basaría en concepción alguna acerca de determinados fines humanos universalmente compartidos. (Rorty, 1991, p. 102)

En una sociedad liberal, la discusión de los asuntos públicos debe atender dos cuestiones centrales: el equilibrio entre las necesidades de paz, de bienestar y de libertad en el caso de que alguna de estas metas deba sacrificarse a favor de las demás y las formas de estimular la igualdad de oportunidades para que los ciudadanos puedan desarrollar sus intereses.

El ironista representa la figura opuesta a la del metafísico. El metafísico es un pensador que afirma la existencia de un mundo en el que existen cosas que comportan esencias reales e independientes del vocabulario con el que se hace referencia a esas cosas. Los metafísicos entienden que una de las tareas de la filosofía es proporcionar un elemento de cohesión social. Existe una diferencia significativa entre una perspectiva liberal ironista y una configuración liberal de carácter metafísico. El ironista liberal cree que es posible evitar la crueldad y la humillación de los otros a través de la redescripción; para un ironista, el reconocimiento de ser susceptible de actos de crueldad y humillación es una condición suficiente para promover conductas que eviten ese tipo de comportamiento hacia otras personas. En la perspectiva liberal de un pensador metafísico, el reconocimiento de un sentimiento común constituye un motivo endeble para promover actos benévolos. Para un liberal metafísico, el deseo de evitar la crueldad y la humillación de los otros requiere de un respaldo argumentativo que ponga en evidencia una esencia humana común.

En una cultura metafísica, la poesía, la novela y cualquier otro de los denominados textos de ficción constituyen obras al servicio de las fantasías privadas de la gente; los tratados teológicos y filosóficos -así como los manuales de moral- son, en cambio, el tipo de obras que pueden argumentar adecuadamente en favor de una determinada forma de vida social. En una biblioteca metafísica, los textos de ficción se agrupan en anaqueles distantes de aquellos que comportan obras dedicadas a regir la vida pública. Por el contrario, en una cultura ironista, cualquiera de los denominados textos de ficción que contribuya en la descripción de actos de crueldad y humillación entre seres humanos puede resultar útil para fines públicos. En este sentido, una biblioteca ironista liberal puede organizar sus textos no en función de un reflejo de algún supuesto orden natural, sino en función del uso que pueda hacerse de las obras literarias que conforman la cultura de la comunidad.

\section{Los estantes de una biblioteca ironista y liberal}

Para Jorge Luis Borges (1984): "La imposibilidad de penetrar el esquema divino del universo no puede, sin embargo, disuadirnos de planear esquemas humanos" ( $p$. 708). En 1952, el mismo Borges sospechaba de la justicia que pudiera comportar el hecho de que la decimocuarta edición de la "Encyclopaedia Britannica" haya suprimido el artículo sobre John Wilkins. Esta sospecha se justifica en la abundancia de las felices 
curiosidades $^{3}$ que contiene su obra especulativa. Entre esas curiosidades, se encuentran la teología, la fabricación de colmenas transparentes y la empresa de establecer los principios de un lenguaje universal que el mismo Wilkins acometiera en 1664 .

La clasificación lingüística de Wilkins puede parecer caprichosa; no obstante, "no hay clasificación del universo que no sea arbitraria y conjetural" (Borges, 1984, p. 708) y, a menos que no se asuma la imposibilidad de "penetrar el esquema divino del universo", la idea de que existe una única manera de catalogar textos resulta más que dudosa ${ }^{5}$.

En una cultura liberal de carácter metafísico, la teología, la filosofía y la ciencia constituyen saberes que tienen la función de trascender las preferencias privadas de los individuos con la expectativa de alcanzar un ámbito universal y común a todos los seres humanos (Rorty, 1991, p. 112). La representación adecuada, por parte de estas disciplinas, de la auténtica esencia humana constituye el fundamento racional para una ética con la obligación moral de desarrollar una solidaridad humana global. En este marco cultural, las esperanzas sociales están ligadas de modo necesario con el conocimiento teórico que comportan la teología, la filosofía y la ciencia. En una cultura liberal de carácter ironista, en cambio, las relaciones que existen entre la teoría y la esperanza social y entre la literatura y la perfección privada son inversas a las de una cultura liberal de carácter metafísico. En una cultura ironista liberal, las disciplinas que tienen la tarea de promover conductas solidarias "son las disciplinas que se especializan en la descripción intensa de lo privado y lo individual" (Rorty, 1991, p. 112). Desde esta perspectiva, las novelas, las producciones etnográficas de los antropólogos y cualquier obra literaria que estimule la sensibilidad al dolor de los otros son las disciplinas que comportan las expectativas de construir un mundo más humano. En esta cultura ironista y liberal, la filosofía -lejos de constituir el fundamento de las esperanzas sociales- se convierte en un instrumento para el alcance de la perfección privada. Entendida de este modo, una determinada perspectiva filosófica es equivalente a las orquídeas silvestres de las montañas de Nueva Jersey que tanto admiraba el joven Rorty y la organización de una biblioteca ironista liberal puede albergar en un mismo estante obras de Platón o Kant y un volumen sobre la botánica de las orquídeas del este de los Estados Unidos.

\footnotetext{
${ }^{3}$ No hemos de subestimar las curiosidades de Borges ni las de John Wilkins, ya que en entre ellas se encuentran los motivos que provocaron la risa de Michael Foucault y dieron origen a Las palabras y las cosas.

${ }^{4}$ Un ejemplo de la arbitrariedad con la que los seres humanos clasificamos el universo se ofrece en la película estadounidense Forrest Gump. En un pasaje del film dirigido por Robert Zemeckis y protagonizado por Tom Hanks, el personaje describe el lluvioso clima de Vietnam en los siguientes términos: "One day, it started raining, and it didn't quit for four months. We been through every kind of rain there is. Little bitty stinging rain, big ol' fat rain... Rain that flew in sideways." "And sometimes rain even seemed to come straight up from underneath. Shoot, it even rained at night."
}

\footnotetext{
5 Son conocidas las diversas controversias sobre el destino de la biblioteca de Aristóteles. En estas, se destaca la versión de quienes han atribuido a Andrónico de Rodas el catálogo no cronológico, sino temático de la obra del estagirita. La edición y el catálogo de Andrónico han llevado a algunos estudiosos a sostener la atractiva propuesta de que el nombre metafísica refiere no a una temática de los escritos aristotélicos, sino más bien al lugar que el texto ocupaba en la biblioteca. Véase Los escritos perdidos de Aristóteles de Báez, Fernando en $A$ Parte Rei Volumen 24, Año 2002.
} 
Existen dos formas alternativas y diferentes de concebir el diseño de una biblioteca liberal: "Los metafísicos piensan que las bibliotecas están divididas según disciplinas, en correspondencia con los diferentes objetos de conocimiento. Los ironistas las consideran divididas según tradiciones" (Rorty, 1991, p. 159).

La biblioteca del ironista liberal puede dividirse, entonces, en dos grandes secciones. La primera de esas secciones contiene el tipo de obras que contribuyen a la autonomía de la persona, es decir, los libros que promueven una actitud ironista. Se trata de libros "importantes para las contingencias individuales que producen fantasías individuales" (Rorty, 1991, p. 159). La segunda sección de esa biblioteca está integrada por el tipo de textos "que nos ayudan a volvernos menos crueles" (Rorty, 1991, p. 159).

La segunda sección de la biblioteca, que -en consonancia con la definición de Judith Shklar- puede denominarse la sección liberal, se compone de dos estantes. Un primer estante contiene el tipo de libros que advierten a una comunidad acerca de los efectos de las prácticas y las instituciones sociales sobre los demás; un segundo estante alberga los diferentes textos que señalan algunos de los efectos que pueden llegar a tener las individualidades privadas sobre otras personas.

El primer estante de esta segunda sección de la biblioteca puede incluir desde novelas que retraten las prácticas públicas que resultan crueles para algunas personas hasta los informes periodísticos y gubernamentales que den cuenta de la humillación que muchas veces provocan algunas de las prácticas sociales que se consideran naturales. Este estante puede incluir -también- textos referidos a distintas formas de esclavitud, obras que se refieran a las condiciones de pobreza en que viven muchas personas y textos que informen sobre la discriminación que sufren o pueden sufrir algunas personas a causa del funcionamiento de las instituciones públicas.

El segundo estante de la sección liberal de esta biblioteca aloja, sobre todo, "obras de ficción que muestran la ceguera de determinado tipo de personas ante el dolor experimentado por otro tipo de personas" (Rorty, 1991, p. 159). Se trata de la especie de libros que retratan formas concretas de crueldad para con un tipo particular de personas y que muestran:

El modo en que nuestros intentos de autonomía, nuestras obsesiones privadas por el logro de determinada forma de perfección, pueden hacernos olvidar el dolor y la humillación que estamos causando. Son libros en los que se dramatiza el conflicto entre los deberes para consigo mismo y los deberes para con los demás. (Rorty, 1991, p. 160)

Son comunes las bibliotecas en las que se organizan los libros separando en una sección moral la especie de textos cuyo propósito es evitar la crueldad -tanto social como individual- de los tipos de textos que tienen un propósito estético.

Existen dos maneras de contrastar los libros que refieren a la moral y los libros que tienen fines estéticos. Aquellos bibliotecarios que distinguen entre la conciencia -entendida como una facultad humana esencial- y el gusto estético -entendido como una facultad opcional- tienden a dar prioridad, en sus bibliotecas, a las obras que se ocupan de asuntos morales y relegan a un estante inferior aquellos textos que tienen un carácter estético. En cambio, los bibliotecarios que consideran que la esencia de lo humano es el deseo de autonomía del ironista y que para el alcance de dicho deseo son irrelevantes las relaciones con otras personas organizan sus bibliotecas de manera 
opuesta. Estos últimos bibliotecarios hacen de la sección estética de su biblioteca un lugar central y otorgan a los textos referentes a asuntos morales un estante secundario.

Estas dos formas de organizar una biblioteca son escasamente útiles para el ironista liberal y esto se debe a que: "Según la emplean tradicionalmente tanto los "moralistas" como los "estetas", esa distinción [entre moral y estética] no hace sino oscurecer la distinción (...) entre lo que es relevante para la autonomía y lo que es relevante para la crueldad" (Rorty, 1991, p. 160).

Para Rorty, las personas no son portadoras de un yo nuclear que comporta facultades cognitivas, morales o estéticas para la búsqueda de creencias verdaderas, de acciones correctas y de belleza. Esta imagen de la persona es propia de los bibliotecarios que dividen bibliotecas y organizan libros en secciones ordenadas jerárquicamente, pero se trata de una imagen que "deja poco espacio tanto para la ironía como para la prosecución de la autonomía" (Rorty, 1991, p. 160).

La biblioteca del ironista liberal no divide sus estantes jerárquicamente en consonancia con el orden de importancia que tienen las facultades de una supuesta esencia humana. El lugar que un texto tenga en esta biblioteca será asignado solamente en función de la respuesta a la pregunta "¿A qué propósitos sirve este libro?" (Rorty, 1991, p. 161).

La organización de textos en una biblioteca ironista y liberal, como la que propone Rorty, está signada por un humanismo profundo que comporta "una preocupación persistente por los congéneres y la necesidad de extender el espectro de nuestra compasión y empatía hacia aquellos que sufren la injusticia económica, la humillación y la crueldad gratuita" (Bernstein, 2013, p. 235).

\section{La novela como herramienta didáctica para una educación ciudadana}

Existe una disputa entre quienes sostienen que el desarrollo de una cultura literaria es un hecho positivo para la política democrática y quienes desconfían de los aportes que este tipo de cultura puede realizar para generar y mantener el clima de tolerancia propio de las sociedades democráticas.

Quienes desconfían de los aportes que una cultura literaria pudiese hacer para con la política democrática entienden que la tolerancia y la solidaridad que impulsa la democracia se favorecería más y mejor de una cultura centrada en descubrimientos científicos. Aquellos que destacan la importancia de la ciencia y de la objetividad científica para el establecimiento de un clima de tolerancia social sostienen que la argumentación es un elemento esencial tanto para la ciencia como para la democracia. Estos pensadores entienden que la literatura, a diferencia de la ciencia, tiene una actitud hostil para con los procedimientos argumentativos.

Aun cuando Rorty comparte la idea de que la argumentación es esencial para los proyectos de cooperación social, sostiene que la redención -entendida como el conjunto de creencias dotadas, siquiera hipotéticamente, de la capacidad de poner fin, de una vez por todas, al proceso de reflexión sobre lo que conviene o no hacer con nuestras vidas- es un asunto individual y privado. Del mismo modo en que la Ilustración difundió la tolerancia religiosa al considerar que las necesidades de la sociedad no deben ser equiparadas con las necesidades del individuo, la cultura literaria promueve 
la difusión de una tolerancia filosófica y científica para la deliberación social. Se cree conveniente que los ciudadanos de una comunidad democrática puedan soslayar sus intereses filosóficos o científicos para cualquier deliberación política. En términos de Rorty: "Esto implica reconocer que los ciudadanos de una sociedad democrática deberían dejar en casa sus esperanzas privadas de autenticidad y autonomía al reunirse para deliberar acerca de lo que es preciso hacer" (Rorty, 1991, p. 185).

Para los miembros de una cultura literaria, el único aporte de relevancia que la ciencia puede realizar a la política reside en proporcionar un modelo de honestidad, tolerancia y confianza; sin embargo, esa contribución es una cuestión que no depende de los resultados científicos, sino del tipo de procedimientos que son propios de los miembros de una comunidad científica.

El novelista checo Milan Kundera ha sugerido que "la novela es el género característico de la democracia, el género más estrechamente vinculado a la lucha por la libertad y la igualdad" (Rorty, 1993, p. 104). Para Kundera, el tipo de saber que pone en juego la novela es diferente del saber teórico propio de los filósofos. El filósofo quiere verse a sí mismo como alguien que trasciende la realización de un proyecto privado, desea enmarcar sus expectativas personales en un contexto más amplio. En esta aspiración, relaciona sus obsesiones privadas (su filosofía) con la existencia de alguna entidad oculta que determina el curso de los asuntos humanos. Las metáforas más comunes que han aportado los filósofos son metáforas de acercamiento a algún tipo de entidad no humana; son metáforas que, de algún modo, clausuran la validez de otras.

Rorty cree que:

Desde el punto de vista de Kundera, el enfoque esencialista de los asuntos humanos por parte del filósofo, su intento de sustituir la aventura, la narrativa y el azar por la contemplación, la dialéctica y el destino constituye una forma insincera de decir: lo que me importa a mí tiene prioridad sobre lo que te importa a ti, me da derecho a ignorar lo que te importa a ti, porque yo estoy en contacto con algo -la realidad- con lo cual tú no estás. (Rorty, 1993, p. 111)

El discurso filosófico comporta un gusto por la teoría que contrasta con el gusto del novelista por la narrativa. La actitud del filósofo está emparentada con la del sacerdote ascético (Rorty, 1993, p. 108). El filósofo, en la obsesión por hallar un léxico que pueda dar cuenta de entidades que expliquen de manera correcta el curso de los acontecimientos humanos, tiende a olvidar que su búsqueda no es sino un proyecto más entre tantos otros proyectos privados $\mathrm{y}$, por consiguiente, olvida el carácter obsesivo de su propia búsqueda.

Los proyectos privados de los filósofos, en muchos de los casos, han resultado de utilidad social. Aun cuando la actitud ascética del filósofo lo impulse en la búsqueda de un vocabulario distinto y ajeno al vocabulario de su comunidad, su búsqueda puede resultar un aporte comunitario. En este sentido, Rorty expresa lo siguiente:

El resultado de intentar encontrar un lenguaje diferente al de la tribu ha sido enriquecer el lenguaje de generaciones posteriores de esa tribu. Cuantos más sacerdotes ascéticos pueda permitirse apoyar una sociedad (...) tanto más rico $y$ diverso es probable que resulten el lenguaje y los proyectos de esa sociedad. Las derivaciones de los proyectos privados de purificación tienen a la postre una enorme utilidad social. (Rorty, 1993, p. 109) 
El gusto por la teoría y las metáforas que los sacerdotes ascéticos persiguen para situarse más allá de su comunidad, en principio, no constituyen ningún obstáculo para la convivencia social. Sin embargo, esa disposición propia de algunos intelectuales deviene en síntoma de una patología social violenta en el momento en que se extravía en su propia obsesión, olvida que su proyecto tiene un alcance privado y que no puede (ni debe) ser impuesto a sus conciudadanos. Este olvido y sus consecuencias hacen que las aspiraciones teóricas se conviertan en herramientas inútiles y hasta riesgosas para la vida social.

Para Kundera, las ventajas sociales de la novela respecto de géneros literarios como la filosofía estriban en el hecho de que "La novela es el paraíso imaginario de los individuos, es el territorio en el que nadie posee la verdad (...) en el que todos tienen derecho a ser comprendidos" (Kundera, 1989, p. 121). El paraíso que Kundera designa con la expresión novela no es distinto del paraíso que conforma la utopía democrática rortyana. Así como en la novela de Kundera, en la utopía democrática de Rorty, nadie puede atribuirse algo como "La Verdad" para su propio proyecto privado:

Una utopía democrática sería una comunidad cuyas principales virtudes intelectuales serían la tolerancia y la curiosidad, más que la búsqueda de la verdad (...) en semejante comunidad todo el mundo puede hacer lo que desea si no perjudica a nadie mientras lo hace. (Rorty, 1993, p. 112)

La novela, en tanto género literario en el que nadie posee la verdad, comporta una contribución para el recuerdo de que el tipo de proyecto propio de los filósofos no es otra cosa que una obsesión privada. En la interpretación de Rorty, la novela, tal como la concibe Kundera, es un escenario en el que conviven múltiples idiosincrasias discursivas ávidas de novedad. En este sentido, la novela no evalúa las metáforas por un mayor o menor acercamiento hacia algún tipo de entidad prelingüística ni tiene la pretensión de acallar voces erróneas. La novela es un género que estimula, de manera indefinida, el surgimiento de nuevas metáforas y este estímulo comporta una receta terapéutica para la prevención de proyectos privados que han olvidado lo que son. Si se abandona la expectativa del sacerdote ascético de hallar un vocabulario incontaminado de propósitos e intereses humanos, entonces, se puede comprender que:

El relato que uno se cuenta a sí mismo respecto de quién es y por qué actúa como lo hace -la novela de la propia vida- no es sino una de las muchas posibles narraciones que pueden referirse. [Y] se admitirá que el parecer de los hombres y las mujeres honestos podría diferir en cuanto a la determinación de cuál de esos relatos haya de considerarse verdadero. (Rorty, 2010, p. 119)

En la medida en que se pueda constatar que el propio proyecto privado convive con una multiplicidad diversa de otros tantos proyectos, se dejará de insistir en la justificación del proyecto propio para ejercer algún tipo de dominación sobre los demás. La novela de Kundera es "un paraíso de individuos en el que nadie tiene derecho a dominar" (Rorty, 1993, p. 113).

Para Rorty:

Una sociedad que tomase su vocabulario moral de las novelas más bien que de tratados ontoteológicos u óntico-morales no se formularía preguntas sobre la naturaleza humana, sobre el objeto de la vida humana o sobre el significado de la vida humana. Más bien se preguntaría qué podemos hacer para aguantarnos mutuamente, cómo podemos disponer las cosas para estar lo más cómodos en- 
tre nosotros, cómo pueden cambiarse las instituciones para que el derecho de cada cual a ser comprendido tenga mejor oportunidad de ser atendido. (Rorty, 1993, p. 117)

Para los miembros de una comunidad que han dejado atrás el impulso de imponer sus propias fantasías privadas a sus conciudadanos, el horizonte político de la comunidad no requiere de autoridad epistemológica alguna. En cambio, para los miembros de una comunidad democrática, el único problema político reside en tolerar fantasías alternativas y no en eliminar las fantasías de los demás en aras de algo como la verdad (Rorty, 2002, p. 111).

La propuesta rortyana es, en palabras de Richard Bernstein, la de un humanista que "soñó con un tiempo en que los filósofos finalmente pudieran renunciar a su obsesión con la representación, la verdad, la objetividad y la realidad" (2013, p. 236) para apuntar su mirada hacia aquellas herramientas que puedan hacer de los miembros de la propia comunidad personas más solidarias.

\section{Conclusiones}

Para Richard Rorty, cualquier perspectiva filosófica que intente conciliar, de manera no circular, los intereses privados con la vida pública constituye un proyecto imposible. Una comunidad democrática que asume la distinción entre lo público y lo privado puede distinguir en su bagaje cultural entre textos en los que predomina la búsqueda de autonomía privada y obras cuyo propósito es promover las instituciones públicas de la propia comunidad. Estos diferentes productos culturales no deben provocarnos la tentación de elegir entre unos u otros. La propuesta rortyana consiste en darle a esos productos la misma importancia y usarlos con fines diferentes.

La imposibilidad de sintetizar los intereses privados con las esperanzas públicas en un proyecto único redunda en el trazado de la figura que Rorty denomina el ironista liberal, figura que el mismo norteamericano contrapone a la del liberal metafísico.

Para un liberal metafísico, la filosofía comporta, entre sus funciones, la tarea de proporcionar argumentos que aseguren la cohesión social. Este tipo de pensador desea evitar la crueldad y la humillación a través de una sólida cadena argumentativa que aspira a evidenciar una esencia humana común. Para un ironista liberal, en cambio, la herramienta pública más conveniente para evitar los actos de crueldad no es la argumentación, sino la redescripción. En este sentido, el reconocimiento de sí mismo como alguien susceptible de actos de crueldad y humillación es una condición suficiente para promover conductas que eviten ese tipo de comportamientos.

La organización de una biblioteca en el marco de una cultura metafísica comporta la idea de que la poesía, la novela y otros de los denominados textos de ficción constituyen obras al servicio de las fantasías privadas de la gente, mientras que los tratados teológicos y filosóficos son el tipo de obras que pueden argumentar adecuadamente en favor de una determinada forma de vida social. Por el contrario, en la organización de una biblioteca en el contexto de una cultura ironista, cualquiera de los denominados textos de ficción que contribuya en la descripción de actos de crueldad y humillación entre seres humanos puede resultar útil para fines públicos. Una biblioteca ironista liberal organiza sus textos no en función de un reflejo de algún supuesto orden natural, sino en función del uso que pueda hacerse de las obras literarias que conforman la cultura de la comunidad. 
Para Rorty, en una biblioteca ironista liberal, la ficción puede ser catalogada como un producto cultural de valor público. En tanto género literario en el que nadie posee la verdad, ella comporta una contribución para el recuerdo de que el tipo de proyecto propio de los filósofos no es otra cosa que una obsesión privada. En la interpretación de Rorty, los textos de ficción constituyen un escenario en el que conviven múltiples idiosincrasias discursivas. Estos textos no albergan la intención de conmensurar metáforas o la pretensión de acallar voces erróneas.

\section{Referencias bibliográficas}

Bernstein, R. J. (2013). El giro pragmático. México: Anthropos.

Borges, J. L. (1984). Obras completas 1923-1972. Buenos Aires: Emecé editores.

Foucault, M. (1968). Las palabras y las cosas. Una arqueología de las ciencias humanas. México: Siglo XXI.

Kundera, M. (1989). El arte de la novela. Barcelona: Tusquets.

Rorty, R. (1991). Contingencia, ironía y solidaridad. Barcelona: Paidós.

Rorty, R. (1993). Ensayo sobre Heidegger y otros pensadores contemporáneos. Escritos filosófi$\cos$ 2. Barcelona: Paidós.

Rorty, R. (1996). Objetividad, relativismo y verdad. Escritos filosóficos I. Barcelona: Paidós.

Rorty, R. (1998). Pragmatismo y política. Barcelona: Paidós.

Rorty, R. (2002). Filosofía y futuro. Barcelona: Gedisa.

Rorty, R. (2008). El pragmatismo, una versión: antiautoritarismo en epistemología y ética. Barcelona: Ariel.

Rorty, R. (2010). Filosofía como política cultural. Escritos filosóficos 4. Madrid: Paidós. 